\title{
LA PATRIA EN EL DISCURSO POLÍTICO DE PABLO IGLESIAS: LA CONSTRUCCIÓN DEL CONCEPTO DE PATRIOTISMO CONSTRUCTIVO A TRAVÉS DEL LENGUAJE METAFÓRICO
}

\author{
Javier Olloqui Redondo \\ Universidad Complutense de Madrid \\ javierolloquiredondo@ucm.es
}

\begin{abstract}
RESUMEN: Desde la Guerra de la Independencia en 1808, la concepción de patriotismo en España ha estado mayoritariamente ligada a ideologías nacionalistas. El surgimiento y repercusión política de la formación 'Podemos' ha suscitado el replanteamiento de la cuestión del patriotismo y de qué significa ser patriota hoy en día. A través del discurso de sus representantes, esta formación ha enfocado la cuestión de manera novedosa para el contexto socio-cultural español, proponiendo una posición centrada en el ensalzamiento de valores sociales o populares. En este sentido, el análisis del uso metafórico del lenguaje utilizado en el discurso de su líder, Pablo Iglesias, al abordar cuestiones patrióticas nos ayuda a comprender cómo se evoca y articula la idea de 'patriotismo constructivo'. Así, llegamos a la conclusión de que su discurso respalda la teoría propuesta en la literatura. Sin embargo, este análisis nos permite revisar las características de dicho patriotismo identificadas en planteamientos previos.

PALABRAS CLAVE: patriotismo, lenguaje metafórico, discurso político, Pablo Iglesias.
\end{abstract}

\section{HOMELAND IN PABLO IGLESIAS'S POLITICAL DISCOURSE: HOW METAPHORICAL LANGUAGE CONTRIBUTES TO THE SHAPING OF CONSTRUCTIVE PATRIOTISM}

ABSTRACT: Since the War of Independence in 1808, the notion of patriotism in Spain has been mostly related to nationalistic ideologies. The emergence and repercussion of the relatively new political party 'Podemos' has triggered the reconsideration of the concept of patriotism and what it means to be a patriot nowadays. Through the discourse of its members, this political party has tackled the issue in a novel way for the Spanish socio-cultural context, adopting a position where social and popular values are emphasised. In this regard, the analysis of Pablo Iglesias's (Podemos's leader) discourse sheds light on how the idea of constructive patriotism is evoked and shaped by virtue of using metaphorical language when addressing patriotic issues. Finally, we conclude that his 
discourse endorses most theoretical accounts proposed in the literature. However, the analysis allows for the revision of the features identified as characteristic of this kind of patriotism in previous approaches.

KEYWORDS: patriotism, metaphorical language, political discourse, Pablo Iglesias.

Recibido: 31/03/2016. Aceptado: 06/06/2016

\section{Introducción}

Este artículo pretende ofrecer un análisis de cómo el uso de metáforas puede contribuir a la formación y definición del concepto de patriotismo. Concretamente, la presente contribución se centra en la idea de 'patriotismo constructivo' (antítesis del 'patriotismo ciego') y cómo esta se articula a través del uso metafórico del lenguaje en el discurso político. Tal y como el siguiente análisis tratará de mostrar, la aplicación de un análisis metafórico puede ser de gran ayuda para arrojar luz sobre los mecanismos que dan forma a las distintas dimensiones del patriotismo tal y como se describen -especialmente- en el trabajo de Staub (1991; 1997), revisando la teoría existente y replanteando algunos de sus postulados. En esta ocasión, el referente será el líder de Podemos -Pablo Manuel Iglesias Turrión-, un partido que en su corta vida ha revolucionado el panorama político español, posicionándose en un espacio que hasta ahora estaba reservado a los dos mayores partidos de los últimos 34 años, el Partido Popular (PP) y el Partido Socialista Obrero Español (PSOE). Antes de embarcarnos en el análisis, conviene explicar brevemente cómo ha sido concebida la idea de patriotismo en España hasta el contexto actual para así entender lo novedoso del enfoque que el partido de Iglesias le ha dado a dicho concepto.

Desde la Guerra de la Independencia contra Francia en 1808, la idea de patriotismo y sus fenómenos derivados (p. ej. ser un patriota, tener sentimientos patrióticos...) en España habían estado estrechamente relacionados al nacionalismo e ideas chovinistas, que, a su vez, suelen relacionarse con ideologías a la derecha del espectro político (Aymes 2004). ${ }^{1}$ En consecuencia, las estrategias discursivas que ensalzaban el patriotismo para ganar simpatizantes de cara a

1. En este sentido, resulta interesante la contribución de Sullivan et al. (1992), quienes aseguran que la cuestión del patriotismo jugó un papel crucial para que George H. W. Bush ganara las elecciones presidenciales de Estados Unidos en 1988. Esto nos da una idea de la importancia que tiene el tema en determinadas sociedades y contextos culturales. 
las citas electorales habían sido especialmente explotadas por los partidos considerados de derecha en España. Más recientemente, sin embargo, otras formaciones más a la izquierda del espectro político -como el PSOE- han tratado de elaborar una noción del patriotismo más alejada de los sentimientos puramente nacionalistas. Se trata de una concepción que articula la idea de patriotismo a través de la evocación de la Constitución y la defensa de la misma (cf. Muro y Quiroga 2005)². Esta concepción del patriotismo ha sido, además, abanderada por Albert Rivera, líder de Ciudadanos ${ }^{3}$. Lo novedoso del enfoque patriótico de Iglesias y de su partido es el énfasis puesto en aspectos más sociales o populares a la hora de evocar dicha noción. Tal y como se analizará más adelante, el discurso de Iglesias trata de asimilar y acercar el concepto de 'patria' al de los habitantes del Estado o la Nación sobre el cual se erige dicho concepto (en este caso, España), estableciendo cuestiones como la soberanía nacional o el Estado del bienestar como pilares básicos para la articulación de dicho concepto. Se trata, pues, de una resignificación de la noción de patria que trata de evocar una concepción menos etnocéntrica que, a su vez, se asocia al concepto de patriotismo constructivo. Esta maniobra discursiva ha suscitado las críticas por parte de otros partidos, haciendo del patriotismo un tema candente en la campaña electoral de junio de $2016^{4}$. Así, el discurso de Iglesias servirá de estudio de caso para analizar cómo la clase política hace uso del lenguaje metafórico para elaborar el concepto de patriotismo constructivo en la era contemporánea.

Para ello, el presente artículo se valdrá de la siguiente estructura. En la sección 2, se abordará la concepción de patriotismo y cómo esta ha sido analizada por diversos autores en la segunda mitad del siglo XX. Además, se ofrecerá un breve resumen de la importancia del lenguaje metafórico para el lenguaje y pensamiento en general y el lenguaje y pensamiento político en particular, incidiendo en los planteamientos teóricos más básicos para entender el procedimiento de formación e interpretación de metáforas. En la sección 3 detallaremos la meto-

2. Sirva como ejemplo el artículo escrito por el ya fallecido exdiputado socialista Gregorio Peces Barba en el diario El País el 10 de noviembre de 2011, al cual se puede acceder a través de este enlace: <http://politica.elpais.com/politica/2011/11/10/actualidad/1320951981_599810.html>.

Para un análisis más actual de la relación entre el PSOE y su líder (Pedro Sánchez) con su idea de “patriotismo integrador”, se recomienda la lectura del artículo de Miguel González publicado en El País el 22 de junio de 2015, en el que se recoge la opinión de diversas personalidades académicas: <http:// politica.elpais.com/politica/2015/06/22/actualidad/1434998967_088460.html>.

3. Léase la noticia publicada por Juan José Mateo en el diario El País el 6 de julio de 2015, <http:// politica.elpais.com/politica/2015/07/05/actualidad/1436119555_269568.html>

4. Véase el artículo publicado por Francesco Manetto en El País el 11 de junio de 2016, <http:// politica.elpais.com/politica/2016/06/10/actualidad/1465545127_298093.html>. 
dología que nos ayudará para proceder al análisis del corpus seleccionado. La sección 4 contendrá el análisis metafórico de los pasajes recopilados en los que se aborde el tema del patriotismo. Tras ello, la sección 5 se centrará en considerar las implicaciones derivadas del análisis para culminar con una sucinta conclusión en la sección 6, que tratará de recopilar y establecer los aspectos más relevantes de la investigación.

Antes de proceder, cabe apuntar brevemente qué tipo de metáforas serán consideradas 'patrióticas' o que tengan que ver con la patria. En primer lugar, hay que especificar que los conceptos de 'patria' y 'país' o ‘Estado’ no son sinónimos ya que no estimulan el mismo marco cognitivo. Sin embargo, como se acaba de mencionar, el concepto de 'patria' se articula en torno al concepto de 'Estado-nación', ya que el segundo es el ente legal y administrativo que sustenta al primero, que, por su parte, representa una idea más abstracta y emocional. Además, no es posible entender la articulación del sentimiento patriótico por parte de Iglesias si no es en estrecha relación con la administración del Estado y la crítica a la mala gestión del mismo (característica clave del patriotismo constructivo, como se verá en la sección 2). En este sentido, las nociones de soberanía nacional y Estado del bienestar son de especial relevancia, ya que sobre ellas se fundamenta la idea de patria de Iglesias. Por tanto, aquellas metáforas que estimulen el marco cognitivo de 'país' entendido como Estado-nación soberano serán consideradas válidas para nuestro análisis, teniendo cabida al lado de otras metáforas que estimulen el marco cognitivo de 'patria' más directamente al hacer referencia al sentir patriótico, a los patriotas, etc.

\section{Estado de la cuestión}

\subsection{Los conceptos de 'patriotismo ciego'y 'patriotismo constructivo'}

Schatz et al. (1999) definen el patriotismo como una de las formas más importantes de cohesión grupal en el mundo contemporáneo. Su persuasiva apelación al orgullo nacional y el espíritu de unidad colectiva cubre ciertas necesidades psicológicas de determinados grupos sociales al proporcionar a sus miembros un sentimiento de pertenencia a una comunidad. Este sentimiento, a su vez, satisface el deseo de conexión y afiliación social así como la necesidad de seguridad y protección (Bader 2006). Pero, ¿qué es el patriotismo? Frecuentemente, se asocia el patriotismo al sentimiento de devoción o amor a la patria (OED 2003; RAE 2014). Schatz et al. (1999) añaden que, por lo general, el patriotismo está ligado a una iden- 
tificación positiva con la patria además de un apego afectivo a la misma, algo suscrito por diversos autores (p. ej. Huddy y Khatib 2007; Finelli y Zogmaister 2015).

Conviene, por tanto, no confundir patriotismo con nacionalismo, ya que el segundo implica una visión más chovinista de la patria (véanse Davidov 2011; Qari et al. 2012). Por poner un ejemplo cercano, dos de las manifestaciones más notables del nacionalismo en España son la concepción de la Corona como elemento unificador histórico y la defensa del castellano como lengua dominante en comunidades con lenguas cooficiales como País Vasco y Cataluña (Muro y Quiroga 2005). Sin embargo, el patriotismo puede adoptar otras formas y manifestaciones tal y como se apunta en la primera sección del artículo. Pese a ello, a menudo las ideas de patriotismo y nacionalismo se entrelazan y son usadas de manera sinónima (Schatz et al. 1999).

Por ello, los primeros enfoques que trataban la cuestión del patriotismo (p. ej. Adorno et al. 1950), tendían a definir el patriotismo como un apego incondicional a los valores culturales nacionales, así como la aceptación absoluta de las dinámicas colectivas prevalentes y el rechazo a otros sistemas culturales ajenos al propio. Esta descripción dio paso a nuevos enfoques que analizaron el fenómeno desde una perspectiva diferente que podría considerarse más abierta y menos etnocéntrica (Schatz et al. 1999). Por ejemplo, Sommerville (1981) afirma que el fenómeno del patriotismo posee dos caras; por un lado está una vertiente obcecada y casi ignorante y, por otro, una visión más razonable y abierta a la crítica. Su trabajo ha sido desarrollado más tarde por Staub (1991; 1997), quien propone una denominación específica para diferenciar blind patriotism (patriotismo ciego) de constructive patriotism (patriotismo constructivo) ${ }^{5}$. Según Staub (1997), el patriotismo ciego se caracteriza por el apoyo incondicional a la patria, una actitud rígida donde no hay espacio para la crítica. En cambio, el patriotismo constructivo es definido como el apego y la consideración al bienestar de los miembros del grupo propio con una actitud inclusiva hacia el resto de seres humanos respetando sus derechos y libertades, algo que Staub (1989) describe como "lealtad crítica". En este sentido, ambas vertientes son patrióticas en tanto en cuanto ambas están basadas en sentimientos de apego y afecto por la patria (Schatz et al. 1999).

Así pues, diversos autores dan cuenta de las principales diferencias y similitudes entre patriotismo ciego y patriotismo constructivo, las cuales se resumen en la Tabla 1.

5. Otras definiciones han sido propuestas en la literatura. Por ejemplo, Parker (2010) denomina patriotismo simbólico a la idea de patriotismo constructivo de Staub. 
Tabla 1. Enumeración de las principales características del patriotismo ciego y el patriotismo constructivo según los principales académicos que han analizado la cuestión

\begin{tabular}{|c|c|}
\hline PATRIOTISMO CIEGO & PATRIOTISMO CONSTRUCTIVO \\
\hline $\begin{array}{l}\text { a) Los patriotas ‘ciegos’ son leales a y están } \\
\text { orgullosos de su país (Livi et al. 2014; } \\
\text { Schatz et al. 1999). }\end{array}$ & $\begin{array}{l}\text { a) Los patriotas ‘constructivos’ son leales } \\
\text { a y están orgullosos de su país (Livi et al. } \\
\text { 2014; Schatz et al. 1999). }\end{array}$ \\
\hline $\begin{array}{l}\text { b) Se caracteriza por actitudes sumisas a los } \\
\text { líderes (Livi et al. 2014). }\end{array}$ & $\begin{array}{l}\text { b) Se caracteriza por una actitud crítica y a } \\
\text { menudo discordante hacia los líderes (Levi } \\
\text { et al. 2014), normalmente agudizada por } \\
\text { la political efficacy o 'efectividad política' } \\
\text { (Schatz et al. 1999) }{ }^{6} \text {. }\end{array}$ \\
\hline $\begin{array}{l}\text { c) Está relacionado con el RWA o Right- } \\
\text { Wing Authoritarianism (Livi et al. 2014; } \\
\text { Schatz et al. 1999)7. }\end{array}$ & $\begin{array}{c}\text { c) No está relacionado con el RWA (Levi et } \\
\text { al. 2014; Schatz et al. 1999). }\end{array}$ \\
\hline $\begin{array}{l}\text { d) Reafirma los valores tradicionales y } \\
\text { rechaza el universalismo (Livi et al. 2014). }\end{array}$ & $\begin{array}{l}\text { d) Abraza la universalidad y cuestiona los } \\
\text { valores tradicionales (Livi et al. 2014). }\end{array}$ \\
\hline $\begin{array}{l}\text { e) Rechaza la multiculturalidad y la } \\
\text { inmigración (Spry et al. 2007). }\end{array}$ & $\begin{array}{c}\text { e) Apoya la multiculturalidad y los } \\
\text { inmigrantes no son estigmatizados (Spry et } \\
\text { al. 2007). }\end{array}$ \\
\hline $\begin{array}{l}\text { f) Incluye cierto desarraigo del sistema } \\
\text { político (Schatz et al. 1999). }\end{array}$ & $\begin{array}{l}\text { f) A menudo incluye activismo político } \\
\text { (Schatz et al. 1999). }\end{array}$ \\
\hline $\begin{array}{l}\text { g) Los patriotas ‘ciegos’ se preocupan } \\
\text { más por cuestiones relacionadas con la } \\
\text { seguridad y la protección de la cultura } \\
\text { nacional (Schatz et al. 1999) además de la } \\
\text { localización de traidores (Parker 2010). }\end{array}$ & $\begin{array}{l}\text { g) Los patriotas ‘constructivos’ se } \\
\text { preocupan del bienestar de todas las } \\
\text { personas residentes en su país (Staub 1997). }\end{array}$ \\
\hline $\begin{array}{c}\text { h) Los actos simbólicos son más } \\
\text { importantes para sus seguidores (Schatz et } \\
\text { al. 1999). }\end{array}$ & $\begin{array}{l}\text { h) Los actos utilitaristas o instrumentales } \\
\text { son más importantes que los simbólicos } \\
\text { (Staub 1997). }\end{array}$ \\
\hline $\begin{array}{l}\text { i) Los patriotas ‘ciegos’ son relativamente } \\
\text { propensos a mostrar actitudes negativas } \\
\text { hacia los miembros de otros grupos sociales } \\
\text { (Parker 2010). }\end{array}$ & $\begin{array}{l}\text { i) Los patriotas ‘constructivos’ suelen } \\
\text { mantener una actitud abierta ante miembros } \\
\text { de otros grupos sociales (Parker 2010). }\end{array}$ \\
\hline
\end{tabular}

6 El término political efficacy o 'efectividad política’ se refiere a la convicción de que las acciones políticas que uno acometa tendrán el efecto deseado en la conducta política -en este caso de los líderes- (Schatz et al. 1999).

7 El Right-Wing Authoritarianism se refiere a un seguimiento de aspecto autoritario con predisposición a la disciplina y el castigo (i.e. agresión), respeto por la autoridad (i.e. sumisión) y adhesión a los valores convencionales (i.e. convencionalismo) (Levi et al. 2014). 
Cabe apuntar que, tal y como se deja entrever especialmente en los puntos e), g) e i) del patriotismo ciego, esta visión del patriotismo apela a la noción del “nosotros contra ellos” de Van Dijk (1998). A través de esta categorización, las personas ajenas o externas a un determinado colectivo social son estigmatizadas y representadas negativamente por los miembros pertenecientes a dicho colectivo. Sin embargo, tal y como se apreciará en la sección 4, este es un recurso que Iglesias explota para articular su discurso patriótico a pesar de ser algo característico del patriotismo ciego.

Aunque la anterior tabla resume los principales rasgos de ambos tipos de patriotismo identificados por diversos autores, la presente contribución estará centrada en el llamado patriotismo constructivo. El objetivo no es otro que mostrar cómo dicho concepto es puesto en práctica en el discurso político a través del uso figurativo del lenguaje, revisando así las anteriores descripciones a través de un análisis fresco y novedoso.

\subsection{El lenguaje metafórico y su análisis en el discurso político}

El Diccionario de la Real Academia Española (DRAE) define metáfora como la "[t]raslación del sentido recto de una voz a otro figurado, en virtud de una comparación tácita” (RAE, 2014). En el sentido puramente lingüístico, se denomina metáfora a aquella representación de una idea o dominio en términos de otro (Lakoff y Johnson 1980). De este modo, el dominio B (destino) es explicado a través del dominio A (origen) siguiendo el esquema [B es A] o [destino es origen], por el cual ciertas características de A son utilizadas para interpretar B.

Las metáforas han sido consideradas una parte esencial de la retórica desde tiempos aristotélicos (Charteris-Black 2005; Musolff 2012). Sin embargo, tras la publicación de Lakoff y Johnson (1980) Metaphors we live by, estas dejaron de ser concebidas como fenómenos meramente lingüísticos que se usaban como artilugios persuasivos en la retórica. Aparte de ello, las metáforas empezaron a ser vistas como un fenómeno conceptual en su naturaleza, así como uno de nuestros principales vehículos para entender la naturaleza dada su base experiencial (Lakoff y Johnson 1980). A esta teoría se la conoce como Teoría de la Metáfora Conceptual (Conceptual Metaphor Theory originalmente en inglés, CMT en lo sucesivo).

8. Ingroup y outgroup, o ‘us versus them’ en términos de Van Dijk (1998). 
Más recientemente, Fauconnier y Turner $(1998,2002)$ propusieron una teoría que desarrollaba lo expuesto en el trabajo previo de Fauconnier (1994) sobre los llamados mental spaces (espacios mentales) así como el ya citado trabajo de Lakoff y Johnson (1980). Su objetivo no era otro que arbolar una teoría capaz de dar cuenta de los procesos asociativos involucrados en la integración conceptual de dos o más ideas en una sola tal y como se manifiesta en el lenguaje. Dicho marco teórico es ampliamente conocido como la Teoría de la Integración Conceptual (Blending Theory en inglés, BT en lo sucesivo). Esta teoría conecta dos o más dominios (espacios de entrada o inputs) a través de un espacio genérico que proporciona información lo suficientemente abstracta como para ser común a ambos inputs (Evans y Green 2006). Así, se constituye una integration network -o red de integración- cuya culminación es la construcción del blended space -espacio amalgamado o amalgama- ${ }^{9}$ que permite la creación de una estructura emergente encargada de aportar la información ausente en uno o varios -si no todos- los inputs (ibid.). Fauconnier y Turner (2002: 46) ilustran el modelo de red de integración a través de un diagrama básico, adaptado en la Figura 1.

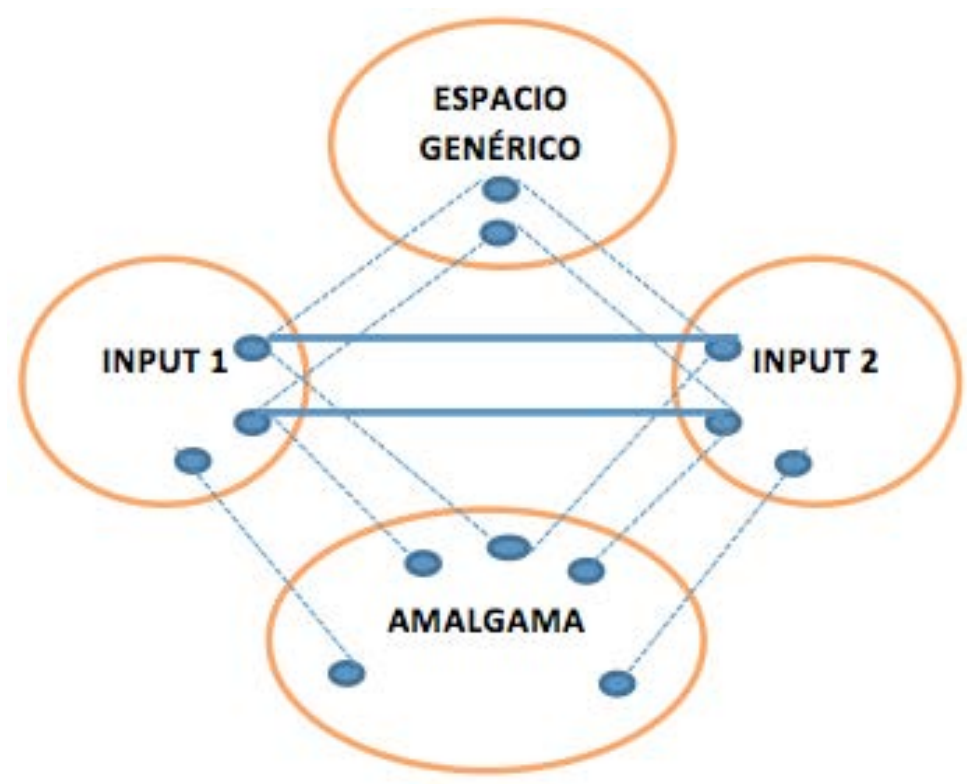

Figura 1. Representación del modelo de integración conceptual según la BT (adaptado de Fauconnier y Turner 2002: 46).

9. Todas las traducciones del original (en inglés) corresponden a las sugeridas por Pascual (2012). 
Así, por ejemplo, la BT sirve para dar cuenta de las inferencias realizadas a través de frases como “este cirujano es un carnicero”. Según Grady et al. (1999), la incompetencia del cirujano es inferida gracias a la integración de ciertos aspectos del input 1 (el cirujano) -la identidad, el paciente, y el lugar donde se realiza el trabajo-junto con ciertos aspectos del input 2 (el carnicero) -como las herramientas que utiliza para realizar el trabajo y los medios a través de los cuales el objetivo es cumplido-. La combinación de estos elementos da lugar a la estructura emergente -amalgama-, la cual hace que se mezclen el objetivo del cirujano (sanar, curar) con las herramientas que utiliza el carnicero en su labor -inadecuadas para la cura- y los medios de este para culminar su labor (carnicería) en lugar de los propios del cirujano (medicina), dando lugar a la idea de incompetencia al cirujano. De manera relevante, Fauconnier (1994, 1997) postula que los distintos espacios mentales que dan lugar a los inputs son activados durante el proceso comunicativo. Esta afirmación ha sido respaldada empíricamente en pruebas psicológicas que muestran cómo las personas accedemos a las metáforas conceptuales en el proceso de producción y comprensión de metáforas tanto convencionales como noveles (Gibbs 2006).

Grady et al. (1999: 1) resumen las similitudes y diferencias entre la CMT y la BT, de las cuales destacamos únicamente las verdaderamente relevantes para los objetivos presentes (en inglés):

[B]oth approaches treat metaphor as a conceptual rather than a purely linguistic phenomenon; both involve systematic projection of language, imagery and inferential structure between conceptual domains; both propose constraints on this projection; and so forth. However, (...) CMT posits relationships between pairs of mental representations, while blending theory allows for more than two; (...) whereas CMT analyses are typically concerned with entrenched conceptual relationships (...), BT research often focuses on novel conceptualizations which may be short-lived.

Las repercusiones del trabajo desarrollado por Lakoff y Johnson (1980) van más allá del terreno estricto de la lingüística cognitiva y afectan otras disciplinas lingüísticas como el Análisis Crítico del Discurso (Critical Discourse Analysis en inglés, CDA en lo sucesivo). Buena muestra de ello son los numerosos enfoques relacionados con las metáforas que han sido propuestos en los últimos años (Musolff 2012) y que, tras la resistencia inicial, han logrado establecerse como una parte importante del análisis del discurso político (Chilton 2005). Así, el análisis sistemático de las metáforas presentes en el lenguaje utilizado por perso- 
nalidades de la política y la aplicación del CDA ha dado lugar a una metodología que Charteris-Black (2004, 2005, 2008, 2009) denomina Análisis Crítico de la Metáfora (Critical Metaphor Analysis en inglés, CMA en lo sucesivo). La razón de ser de esta metodología reside en la importancia capital del uso de metáforas en el discurso político ya que, según Charteris-Black (2005), aparte de tener poder persuasivo, estas: a) contribuyen a la creación de realidades sociales que pueden ser usadas al servicio de cualquier ideología (ver también Núñez-Perucha 2011); b) causan respuestas emotivas y afectivas en el oyente; c) constituyen una característica esencial para la construcción del liderazgo ${ }^{10}$. Por último, es importante tener en cuenta que el lenguaje metafórico puede jugar un papel crucial en una situación donde favorecen una visión de la realidad sobre otras (Chilton 1996).

De este modo, la aplicación del CMA al estudio de la configuración de la idea de patriotismo puede arrojar luz al análisis de cómo se construyen las dos dimensiones del patriotismo en el discurso político. Para el presente artículo, sin embargo, limitaremos el análisis a aquellas metáforas que apoyen la idea de patriotismo constructivo.

\section{Método y corpus seleccionado}

Para llevarlo a cabo, el marco teórico que utilizaremos será el del CMA, ya que nos proveerá de las herramientas básicas para hacer una lectura crítica de los usos metafóricos del lenguaje por parte de Iglesias a través de tres pasos o fases (Charteris Black 2004, 2005):

a) Identificación de la metáfora: se lleva a cabo al identificar la tensión semántica causada por el uso de elementos léxicos en contextos imprevistos.

b) Interpretación de la metáfora. Una vez la metáfora ha sido identificada, se procede a la interpretación de la misma aplicando enfoques cognitivosemánticos a la metáfora. Charteris-Black hace uso exclusivo de la CMT de Lakoff y Johnson $(1980,1999)$ para completar este paso.

c) Explicación de la metáfora. En este último paso se debe dar cuenta de las motivaciones ideológicas de la metáfora analizando el uso de esta junto con otros mecanismos retóricos (p. ej. la metonimia) como respuesta a cierto fenómeno socio-político.

10. Ver Mio et al. (2005) para un enfoque psicolingüístico al respecto. 
Sin embargo, tal y como señalan Grady et al. (1999), la CMT puede a veces fallar en su objetivo de explicar ciertos fenómenos lingüísticos ya que no consigue dar cuenta de componentes que no están explícitos en la metáfora. Más concretamente, al ser un modelo basado en dos dominios (source y target: origen y destino), puede que no logre identificar las inferencias e implicaciones contenidas en ciertas metáforas. En cambio, la BT -al ser, en principio, un modelo basado en cuatro espacios-11 es capaz de dar cuenta de estructuras novedosas (i.e. emergentes) que surgen como resultado de un uso metafórico concreto (Grady et al. 1999). De hecho, Hart $(2008,2011)$ reconoce las consecuencias que este hecho acarrea para los propósitos del CMA y, en consecuencia, propone una alternativa sobre cómo debería establecerse el CMA como marco teórico y analítico. Según el autor, el CMA debería integrar CMT y BT para proporcionar una explicación más desarrollada de los usos metafóricos del lenguaje ya que la BT da acceso a las estructuras emergentes evocadas por los políticos en el transcurso de su discurso (Hart 2008). Es por ello que el presente análisis seguirá el consejo de Hart y se servirá de la BT para asistir a la CMT en aquellos casos donde la explicación de la estructura emergente sea más importante.

Cabe apuntar que la presente contribución pretende proporcionar un abanico de diferentes metáforas relacionadas con la idea de patriotismo con el objetivo último de revisar enfoques descriptivos previos que abordaron la cuestión del patriotismo constructivo. Para este propósito se necesita constituir un registro relativamente amplio de metáforas, de manera que la revisión y evaluación resulte robusta y clara. Por tanto, este artículo no pretende examinar exhaustivamente cada una de las metáforas utilizadas. Los análisis más profundos los dejamos para contribuciones posteriores, centradas en examinar una o varias características concretas del patriotismo.

Antes de proceder al análisis, conviene mencionar que el corpus corresponde a los datos extraídos de la transcripción de nueve mítines de Iglesias entre los años 2014 y 2015². Las metáforas relacionadas con el patriotismo serán analizadas y clasificadas de acuerdo al dominio de destino. Además, se facilitará el

11. La BT permite la inclusión de más de cuatro espacios, dependiendo de la cantidad de inputs contenidos en la red integradora (Fauconnier y Turner 2002).

12. La elección de Iglesias como único representante del corpus responde exclusivamente a criterios prácticos, ya que el líder de Podemos es la cabeza más visible dentro de dicha formación política debido a su fuerte exposición mediática. Otros responsables del partido, como Íñigo Errejón, han fomentado también la idea de patriotismo constructivo, pero su exposición mediática (pese a ser notable) no alcanza los niveles del primero. 
contexto de dichas metáforas donde sea necesario ${ }^{13}$. Como el lector observará, algunos de los contextos incluyen más de una metáfora; en esos casos, las metáforas se analizarán de manera separada, siguiendo el criterio recién mencionado. Por último, algunas de las metáforas utilizadas resultan de la combinación de múltiples metáforas o de metáfora y metonimia. En tales casos, se analizarán únicamente aquellas metáforas más relevantes para el propósito del artículo.

\section{Análisis}

El análisis que viene a continuación, a pesar de estar basado en la metodología propuesta por Charteris-Black (2004, 2005), enfocará el tema de manera distinta, ya que el dominio de destino servirá como punto de partida para el análisis.

\subsection{Metáforas de la patria y el país}

Previsiblemente, las metáforas que hacen mención explícita de la idea de patria, país o Estado-nación son las más comunes en el discurso patriótico de Iglesias. Sus ideas pueden clasificarse en tres dominios de origen distintos: personificación (humanos), económicos (dinero y empresas) y Estado del bienestar.

\subsubsection{Personificación}

La personificación ya ha sido identificada como uno de los mecanismos metafóricos más poderosos en el discurso político (Charteris-Black 2005) y el caso del discurso patriótico de Iglesias no es una excepción.

LOS ESTADOS SON PERSONAS - Esta metáfora conceptual puede dividirse en dos dominios de destino diferentes: uno asociado con una idea más sentimental del Estado-nación (i.e. patria) y otro más cercano a una concepción más política (i.e. país):

- LA PATRIA ES UN GRUPO DE PERSONAS

(1) La patria es tu gente.

13. El lector puede acceder a dicho contexto consultando el Apéndice 1. Para una visualización directa de los mítines de lo cuales se extrajeron las partes del discurso, el lector puede consultar las distintas direcciones URL facilitadas en el Apéndice 2. 
(2) Esa es nuestra patria, la gente.

(3) Ellos [los ciudadanos de España] son mi patria.

\section{- LOS PAÍSES SON PERSONAS}

(4) Ellos [los ciudadanos de España] son el país del que estoy orgulloso.

(5) España es sus gentes, España es sus ciudadanos.

(6) Hay un país que defiende la alegría y la dignidad.

(7) Estoy harto de una concepción de España agresiva (...) que diga a los demás qué lengua tienen que hablar o de qué nación se tienen que sentir.

(8) Porque estás defendiendo a tu país, porque estás defendiendo a tu gente.

Así, podemos establecer las siguientes relaciones (Tabla 2) de acuerdo a las metáforas anteriores:

Tabla 2. Tabla de correspondencias de la metáfora conceptual LOS ESTADOS SON PERSONAS

\begin{tabular}{|c|c|c|}
\hline Estados & $\rightarrow$ & Personas \\
\hline Sistema legal opresor & $\rightarrow$ & Comportamiento agresivo \\
\hline Políticas culturales inflexibles & $\rightarrow$ & Actitud intolerante \\
\hline Apoyo los intereses nacionales & $\rightarrow$ & Defensa de tus semejantes \\
\hline
\end{tabular}

El uso de estas metáforas para abordar el tema de la patria persigue que se identifique a las personas que viven en España (y, por ende, votantes potenciales) con el Estado en sí mismo. Esta estrategia discursiva humaniza la idea de Estado, acortando así la brecha emocional entre Estado y electorado. Por tanto, esta estrategia tiene el potencial de despertar actitudes más comprometidas con la política y el bienestar de las personas que viven en el país y, finalmente, provocar un incremento del activismo político. Además, tal y como hemos visto, Iglesias explota las estrategias de personificación y cosificación estableciendo una serie de correspondencias metafóricas estables en vez de utilizar un amplio número de correspondencias distintas. El objeto de este mecanismo puede ser el intento de arraigo de estas correspondencias o asociaciones propuestas en sus metáforas en el sistema conceptual de su audiencia, sobre todo teniendo en cuenta que la asociación entre los sentimientos patrióticos y el bienestar del prójimo es bastante novedoso en el contexto político-social español. En este sentido, cabe mencionar que, tal y como defiende Glucksberg (1998), las metáforas inclusivas (p. ej. 
DESTINO ES ORIGEN) requieren menos tiempo para ser procesadas que las metáforas-símiles (DESTINO ES COMO ORIGEN). Y este es, precisamente, la manera favorita de Iglesias para comunicar todas las metáforas que usa en general y las de personificación en particular.

\subsubsection{Economización ${ }^{14}$}

Una de las estrategias más destacadas de Iglesias a la hora de usar el lenguaje metafórico tiene que ver con la conceptualización de la patria como un fenómeno económico. En este aspecto, parece haber dos metáforas principales contenidas en la metáfora conceptual LOS ESTADOS SON FENÓMENOS ECONÓMICOS: LA PATRIA ES DINERO y LOS PAÍSES SON MARCAS COMERCIALES:

- LA PATRIA ES DINERO:

(9) Todos esos [los poseedores de grandes cantidades de dinero] solo tienen una patria, su dinero.

(10) No tienen más patria que sus cuentas bancarias.

- LOS PAÍSES SON MARCAS COMERCIALES:

(11) Nuestra patria no es una marca.

(12) Nunca más España como marca para que hagan negocios los ricos.

Parece clara la intención por parte de Iglesias de representar negativamente cualquier correspondencia entre la patria y los temas económico-financieros. Esta vez, consideramos más oportuno representar las asociaciones metafóricas haciendo uso de los espacios mentales propuestos en la BT que los propuestos por la CMT como en la subsección anterior. Esto nos permitirá visualizar más nítidamente cómo el proceso de negativización es llevado a cabo. Tomemos, por ejemplo, la metáfora en (9) y desgranemos las correspondencias metafóricas tal y como aparece en la Figura 2. Como se puede apreciar, el proceso de integración en el espacio mixto o amalgama tiene como consecuencia que la asociación de los sentimientos normalmente asociados a la patria sean, en su lugar, asociados al dinero o a la posesión del mismo. Así, se representa al poseedor de grandes fortunas como una persona que, en lugar de sentir afecto y compromiso por su patria, tiene esos sentimientos por su dinero.

14. Utilizamos esta nomenclatura para referirnos al proceso por el cual ciertos conceptos son representados como fenómenos económicos. 


\subsubsection{Sistema del bienestar}

La asociación entre el concepto de patria y la accesibilidad de determinados servicios públicos es uno de los pilares básicos del discurso patriótico de Iglesias. Considérese el siguiente extracto de uno de sus discursos:

\section{- LA PATRIA ES EL SISTEMA DEL BIENESTAR}

(13) La patria es poder llevar a tus hijos pequeños a una escuela pública. La patria es que el gobierno garantice que a los enfermos de hepatitis se les da la mejor medicación. La patria es que si tu abuelo está muy mayor, va a haber alguien que le cuide. La patria es derecho a que te atiendan en un hospital.

Este pasaje pone de manifiesto la importancia otorgada al acceso al sistema de bienestar de los habitantes de un país por parte de Iglesias como parte de su discurso patriótico. El concepto de patria es relacionado con los derechos humanos y la disponibilidad de servicios públicos para los ciudadanos, poniendo así el bienestar social al frente de lo que significa tener una patria o estar orgulloso de la misma.

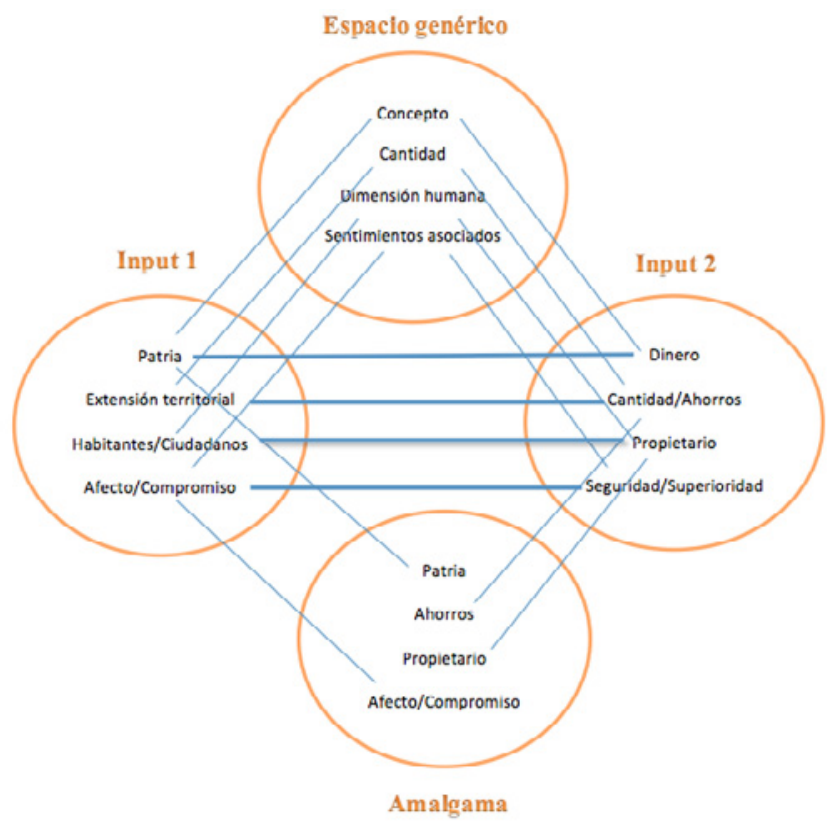

Figura 2. Representación del proceso de integración conceptual implementado por la metáfora LA PATRIA ES DINERO. 


\subsection{Otras metáforas: el "nosotros contra ellos" como elemento articulatorio del patriotismo constructivo}

Además de emplear las personas, la economía y el Estado del bienestar como dominios de origen, Iglesias recurre a otras áreas para evocar la idea de patria y la dimensión del patriotismo constructivo. En este aspecto, la estrategia del "nosotros contra ellos" -sobre la que se construye la base de cualquier ideología (Van Dijk 1998)- se revela crucial para la articulación de dicha dimensión en el discurso de Iglesias. Esta estrategia ya ha sido utilizada como filón para reafirmar el sentimiento de pertenencia en varias clases de discurso (p. ej. político, periodístico...) (ibid.). Así pues, esta estrategia sobresale como elemento articulador de un número de metáforas que buscan la resignificación de la noción de patriotismo a través de la oposición entre el 'nosotros' y el 'ellos'. En esta subsección haremos hincapié en su uso dentro del lenguaje metafórico para representar temas como la soberanía, las medidas políticas de austeridad, la clase social, la traición, los sentimientos patrióticos y los acontecimientos históricos nacionales.

\subsubsection{La soberanía}

\section{- LA SOBERANÍA ES UN OBJETO}

(14) Ellos [los ciudadanos de España] son los depositarios últimos de la soberanía.

(15) [En referencia a los anteriores dirigentes políticos] A los que entregan la soberanía de nuestro país...

El objetivo aparente de esta metáfora es la de convertir un concepto altamente abstracto (a menudo confuso y malinterpretado) como la soberanía en algo accesible y entendible para la audiencia. A su vez, hace énfasis en el valor democrático de la soberanía popular, que aparece amenazada por los anteriores dirigentes en la representación de Iglesias. Es ahí, precisamente, donde el valor articulario del 'nosotros' contra 'ellos' estructura la interpretación de soberanía como elemento fundamental para el sentir patriótico que defiende Podemos. A través de la cosificación, se dibuja un panorama en el que el pueblo (el 'nosotros') es despojado de uno de sus activos más sólidos para la fundamentación de la idea de Estado (sustento principal de la noción de 'patria'): la soberanía nacional. Según esta interpretación, dicho activo es desviado de su legítimo destino por parte del 'ellos', lo cual supone una amenaza para la patria al dañar uno de sus pilares fundamentales. 


\subsubsection{Las políticas de austeridad}

Pese a tener un carácter más coyuntural y menos fundamental que la representación de la soberanía nacional, la representación de las políticas de austeridad implementadas por el gobierno del Partido Popular como dañinas incide directamente en la noción de patria, ya que se conceptualizan como dañinas para el pueblo y, en consecuencia, para su bienestar, punto clave del patriotismo constructivo. Así pues, se representa al 'ellos' como algo perjudicial, dejando para el 'nosotros' la formulación de políticas alternativas que puedan paliar el mal causado por las políticas implantadas por el 'ellos'. Esta estrategia da lugar a la metáfora conceptual LAS POLÍTICAS DE AUSERIDAD SON ACTIVIDADES DAÑINAS, la cual se divide en las siguientes metáforas:

\section{- LAS POLÍTICAS DE AUSTERIDAD SON DELITOS}

(16) [Los responsables del actual gobierno] han querido humillar a nuestro país con esa estafa que llaman austeridad.

En (16), las políticas de austeridad impulsadas por el anterior gobierno de España y otras organizaciones externas como el Fondo Monetario Internacional o el Banco Central Europeo son asociadas con una actividad delictiva como la estafa.

- LAS POLÍTICAS DE AUSTERIDAD SON FUERZAS DESTRUCTORAS

(17) Romper España es privatizar la sanidad, romper España es privatizar la educación.

Así pues, en (17) el discurso de Iglesias ataca las políticas privatizadoras que se implementaron en España tras el inicio de la crisis económica. En la Figura 3 se desmenuza la integración conceptual de los dominios de las políticas por un lado y la destrucción por otro. Como se puede apreciar, la estructura emergente representada en el espacio amalgama representa las consecuencias derivadas de la aplicación de políticas privatizadoras de servicios públicos según Iglesias. Esta identificación de algunas de las políticas recientemente implementadas en España con elementos dañinos y amenazantes sirve para criticar y, hasta cierto punto, demonizar las prácticas políticas de algunos de los anteriores líderes y responsables gubernamentales ('ellos'). 


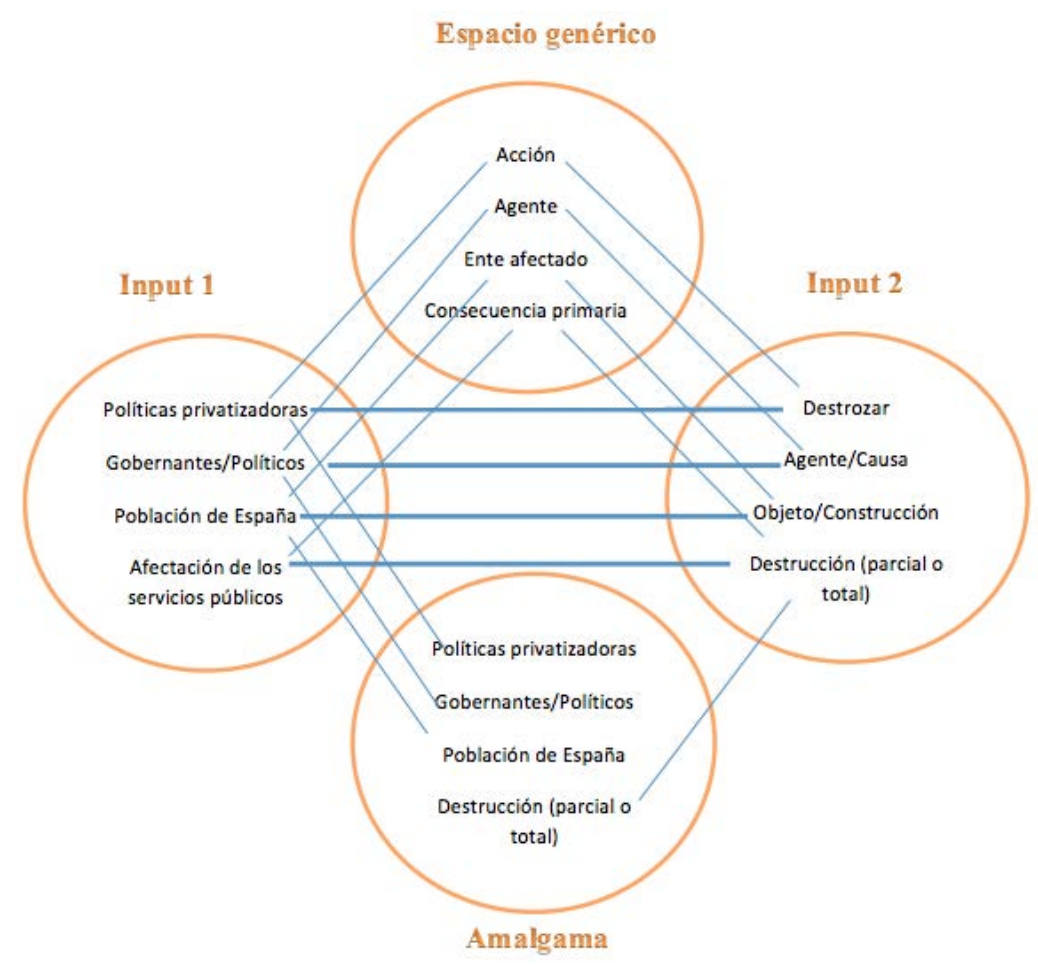

Figura 3. Representación de la integración conceptual de la metáfora LAS POLÍTICAS SON FUERZAS DESTRUCTORAS.

\subsubsection{La clase social}

En esta ocasión, la estrategia articuladora del 'nosotros contra ellos' es llevada a cabo a través de la distinción claramente definida entre 'los de arriba' ('ellos') y 'los de abajo' ('nosotros'). Esta distinción está motivada por la metáfora conceptual espacial LA CLASE SOCIAL ES ELEVACIÓN VERTICAL:

\section{- LA CLASE SOCIAL ES ELEVACIÓN VERTICAL}

(18) Pero necesitamos que nuestros ricos sean responsables y con un mínimo sentido del patriotismo. No puede ser que solo se ajusten el cinturón los de abajo mientras que los de arriba cada vez ganan más.

Tal y como apuntábamos anteriormente, esta metáfora sirve para reafirmar la dicotomía del 'nosotros' contra 'ellos'. Sin embargo, lo verdaderamente 
crucial para nuestro análisis es la atribución implícita de valores patrióticos a 'los de abajo' que Iglesias astutamente indica al reclamar 'responsabilidad' y ‘un mínimo sentido de patriotismo' al 'ellos'. De este modo, el sentido del patriotismo y la responsabilidad patriótica del 'nosotros' es dada por hecho a través de la omisión.

\subsubsection{Sentimientos y actitudes hacia la patria}

Iglesias también destaca la adopción de ciertas actitudes como ejemplos de comportamientos patrióticos y lo hace a través del lenguaje metafórico.

\section{- LOS SENTIMIENTOS SON ACCIONES}

(19) Amar tu patria es indignarte cuando hay gente que tiene que ir a comedores sociales. Amar a tu patria no es llevar pulseras de colores; es indignarte cuando ves que gente que no tiene trabajo no recibe ninguna prestación.

De nuevo hábilmente, Iglesias propone una manera de amar la patria drásticamente contraria al aprecio de actitudes simbólicas, las cuales son, a su vez, explícitamente rechazadas. En su lugar, sugiere que el sentimiento de apego hacia la patria debe estar acompañado por un sentimiento de responsabilidad que provoque una reacción en busca de la solución a situaciones injustas que afectan a la comunidad. En otras palabras, su concepción de amor por la patria es más utilitario o instrumental que simbólico. Una vez más, la manera de amar la patria del 'nosotros' se ensalza, mientras que la del ‘ellos’ se estigmatiza.

\subsubsection{La traición}

En otra astuta maniobra, Iglesias proporciona una novedosa descripción de qué significa ser un traidor a la patria, la cual elabora a través de la metáfora LA EVASIÓN DE IMPUESTOS ES UNA ACTIVIDAD DAÑINA, la cual podemos dividir en dos metáforas distintas:

\section{- LA EVASIÓN DE IMPUESTOS ES TRAICIÓN}

(20) Quien tiene las cuentas bancarias en Suiza o en Andorra tiene un nombre: traidor; traidores a su pueblo. No tienen más patria que su dinero. 


\section{- LA EVASIÓN DE IMPUESTOS ES DESTRUCCIÓN}

(21) Los que rompen España son los que tienen cuentas en Suiza o en Andorra.

De manera similar a la representada en la Figura 3, las consecuencias de evadir impuestos son asemejadas a las derivadas del uso de un material o acción destructiva. Además, su representación como traidores ahonda en la distinción entre el 'nosotros' y 'ellos', ya que los evasores fiscales son ilustrados como entes dañinas, amenazantes con características indeseables para el 'nosotros'. Podemos afirmar que las metáforas relacionadas con 'los de arriba' y las relacionadas con los evasores fiscales muestran una actitud de confrontación -más que de reconciliación- hacia el ‘ellos’.

\subsubsection{Eventos históricos nacionales}

El último aspecto a analizar es la apelación a antiguos héroes que Iglesias utiliza como mecanismo para darle forma a su idea de patriotismo constructivo. En este caso, su estrategia es la de tender un puente entre el pasado y el presente a través de dos metáforas que pueden ser englobadas en otra: LOS EVENTOS PASADOS SON EVENTOS ACTUALES.

- LOS CONTEXTOS SOCIO-POLÍTICOS SON EVENTOS DEPORTIVOS (22) Creo que estamos en una como esa. Podemos ganarle el partido a los Estados Unidos ${ }^{15}$.

- PERSONAJES PASADOS SON PERSONAJES ACTUALES

(23) 2 de mayo de 1808 (...). Fue el pueblo de Madrid, ese que hoy está en la calle con nosotros, el que compró con sacrificio la dignidad frente a una invasión intolerable.

La similitud que Iglesias invoca en (23) entre el levantamiento contra las tropas napoleónicas durante la Guerra de la Independencia y la situación actual tiene como objetivo alimentar el deseo y la moral por la victoria o un desenlace positivo para el 'nosotros'. Sin embargo, en (22) Iglesias -cuidadosamente- evoca

15. En esta ocasión Iglesias está haciendo referencia a la final olímpica de baloncesto masculino (JJ.OO. de Pekín 2008) entre España y Estados Unidos, donde el equipo nacional español se colgó la medalla de plata tras ser derrotado por el equipo nacional norteamericano por un estrecho margen. A pesar de la derrota final, este resultado fue considerado un gran logro por la opinión pública y los medios españoles. 
solo la situación (España plantándole cara a un poderoso rival) y no el desenlace (derrota ajustada) para transmitir únicamente las correspondencias metafóricas adecuadas a su objetivo y lo logra usando el presente verbal. En cambio, el uso del pretérito en (23) identifica el evento mencionado como un proceso finalizado y, por tanto, con un desenlace claro y definido. Esta maniobra está representada en la Figura 4.

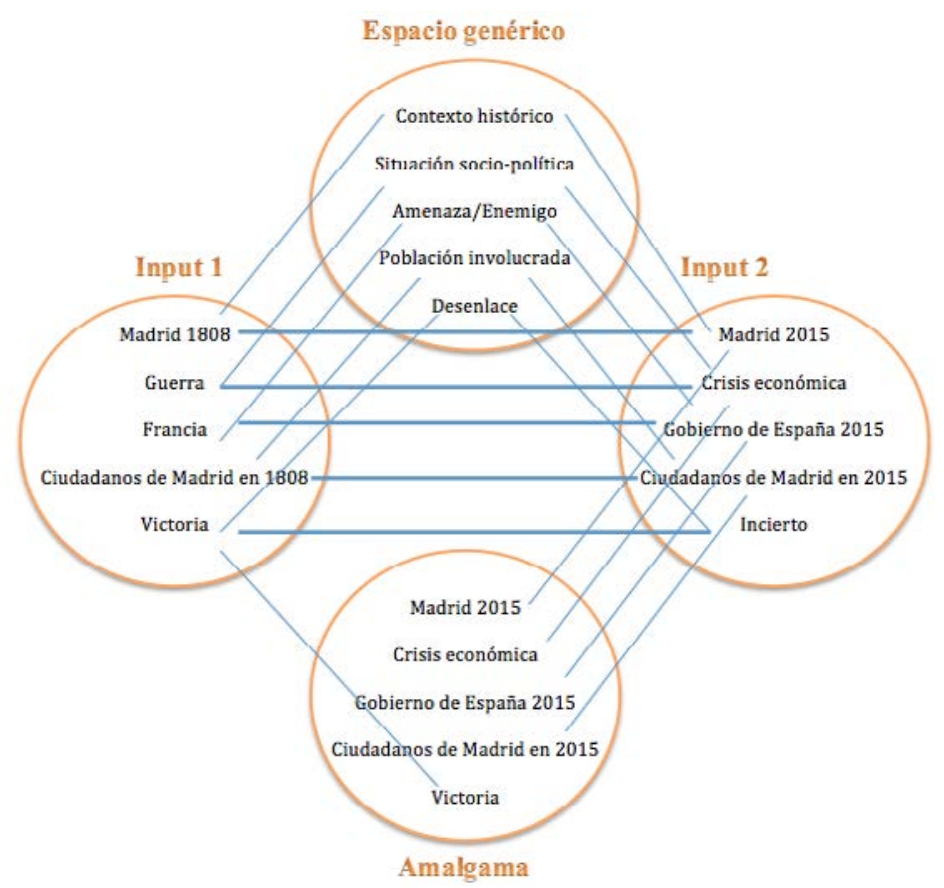

Figura 4. Representación de la integración conceptual de la metáfora LOS EVENTOS PASADOS SON EVENTOS PRESENTES.

\section{Discusión}

Según Charteris-Black (2005), el lenguaje persuasivo pretende bien confirmar o desafiar las creencias establecidas. En el caso de Pablo Iglesias, se puede afirmar que sus destrezas como orador le han permitido cambiar algunas de las concepciones culturales más arraigadas en España explicadas por Aymes (2004), resignificando el concepto de patriotismo en el contexto sociopolítico español. De manera notable, Charteris-Black (2008) destaca el uso de las metáforas para facilitar el cambio conceptual. En este sentido, Iglesias ha 
conseguido convertir la noción de patriotismo en algo no exclusivo de visiones de la patria más conservadoras o constitucionalistas, logrando encontrar un hueco para el patriotismo constructivo en el debate político español. Este es un hecho que no ha pasado por alto en los medios de comunicación españoles (véanse los artículos de Francesco Manetto y Luis Gómez el 24/6/15 y 17/6/14 respectivamente en El País). ${ }^{16}$

Por otro lado, es importante apuntar que la teoría existente acerca de la construcción del patriotismo constructivo se ve apoyada por el análisis realizado al lenguaje metafórico que utiliza Iglesias para abordar cuestiones patrióticas. Sin embargo, hay ciertos aspectos que no han podido ser encontrados al analizar dicho lenguaje metafórico. Paralelamente, hay otros aspectos que han sido hasta ahora omitidos y que el análisis previo nos permite tener en cuenta, al igual que otros que entran en contradicción con las características del patriotismo constructivo proporcionadas por varios autores y listadas en la sección 2 de este artículo. Estos han de ser incluidos en la discusión teórica para, de esta manera, dar una explicación más completa acerca del fenómeno que estamos abordando. Procedemos ahora a un examen conciso de cómo el presente análisis afecta a la teoría existente, siguiendo punto por punto las características apuntadas en la sección 2 (en cursiva) y numerando las metáforas analizadas entre paréntesis y corchete.

a) Los patriotas 'constructivos' son leales a y están orgullosos de su país (Livi et al. 2014; Schatz et al. 1999). Iglesias relaciona el sentimiento de lealtad y apego por la patria a una actitud concreta que persigue mejorar las condiciones de vida de todos los habitantes del país [i.e. (19)]. Esto refrenda el argumento de Finelli y Zogmaister (2015) de que el patriotismo constructivo requiere que el sentimiento de orgullo nacional esté equilibrado con el respeto a los derechos humanos de todos los miembros de la comunidad.

b) El patriotismo constructivo se caracteriza por una actitud crítica y a menudo discordante hacia los líderes (Levi et al. 2014). La conexión que Iglesias establece entre las políticas de austeridad con actividades delictivas por un lado [i.e. (16)] y entre las políticas privatizadoras

16. Artículo de F. Manetto: ¿Qué significa ser patriota para Podemos? <http://politica.elpais.com/ politica/2015/06/24/actualidad/1435174006_888158.html>.

Artículo de L. Gómez: "Defendemos lo bueno del sistema” <http://politica.elpais.com/ politica/2014/06/16/actualidad/1402946493_140110.html>. 
con el deterioro del país por otro [i.e. (17)] son el mejor ejemplo de la actitud crítica hacia los líderes gubernamentales realizada por el líder de Podemos.

c) El patriotismo constructivo no está relacionado con el Right-Wing Authoritarianism (Levi et al. 2014; Schatz et al. 1999). La representación de la soberanía nacional como un objeto de valor perteneciente a los miembros de la comunidad [i.e. (14) y (15)] son el mejor ejemplo del rechazo al autoritarismo en el discurso de Iglesias.

d) El patriotismo constructivo abraza la universalidad y cuestiona los valores tradicionales (Livi et al. 2014). Los usos metafóricos del lenguaje por parte de Iglesias en nuestro corpus no acreditan ni desmienten el apoyo a la universalidad, aunque en (7) sí se lanza un ataque frontal a valores nacionalistas como el uso de una sola lengua en el territorio nacional.

e) El patriotismo constructivo apoya la multiculturalidad y los inmigrantes no son estigmatizados (Spry et al. 2007). La ilustración de España como un país multicultural es llevada a cabo en la estrategia de personificación en España es sus gentes [i.e. (5)]. Significativamente, la palabra 'gente' es utilizada en plural, reconociendo así la presencia de varios grupos sociales dentro de un espacio político común. Por otro lado, la inmigración no es un tema que Iglesias vincule al patriotismo a través del lenguaje metafórico encontrado en nuestro corpus.

f) El patriotismo constructivo a menudo incluye activismo político (Schatz et al. 1999). Tal y como se ha apuntado anteriormente, la personificación [i.e. $(1$ - 8)] del concepto de Estado es susceptible de provocar un sentimiento de compromiso por la patria y la mejora de la vida en ella a través del acortamiento de la brecha entre Estado y población. Además, Iglesias asocia actitudes patrióticas como amar la patria con la reacción contra situaciones injustas [i.e. (19)], una posición íntimamente ligada al activismo político.

g) Los patriotas 'constructivos' se preocupan del bienestar de todas las personas residentes en su país (Staub 1997). El hecho de que Iglesias coligue el concepto de patria con la disponibilidad de servicios públicos típicamente relacionados con el estado del bienestar [i.e. (13)] pone de manifiesto cómo el bienestar social es uno de los estandartes del patriotismo constructivo. 
h) Para los patriotas 'constructivos' Los actos utilitaristas o instrumentales son más importantes que los simbólicos (Staub 1997). Iglesias rechaza explícitamente la identificación de valores patrióticos con actitudes simbólicas que ensalcen los emblemas patrios (p. ej. llevar una pulsera con los colores de bandera nacional). En cambio, tal y como apuntábamos previamente, él trata de asociar el sentir patriótico con aspectos más utilitaristas o instrumentales que conduzcan a la mejora de las condiciones de vida en el país [i.e. (13) y (19)]. Sin embargo, su evocación de acontecimientos históricos nacionales puede ser interpretada como un enaltecimiento de valores simbólicos más que utilitarios, hecho que será sucintamente analizado al final de la sección.

i) Los patriotas 'constructivos' suelen mantener una actitud abierta ante miembros de otros grupos sociales (Parker 2010). Tal y como muestra la estrategia implementada del 'nosotros' contra 'ellos' [i.e. (14 - 23)], Iglesias fomenta una actitud de confrontación más que de reconciliación hacia los miembros de otros grupos socio-económicos. Esto pone en entredicho la validez o aplicabilidad de este punto en cuanto a su vinculación al concepto de patriotismo constructivo.

Aparte de la revisión recién completada, hay otras características del patriotismo constructivo que no han sido reconocidas en la literatura. Concretamente, nos referimos a dos estrategias discursivas que Iglesias realiza a través de expresiones metafóricas: la identificación de un enemigo común y la confrontación contra este por un lado y el ensalzamiento de hazañas nacionales históricas por otro. Así, la acusación y el enfrentamiento contra el traidor es algo en lo que Iglesias no duda en insistir [i.e. (20) y (21)]. Notablemente, esta es una característica que la literatura (p. ej. Parker 2010) ha asociado exclusivamente al patriotismo ciego (ver apartado g) en la columna del patriotismo ciego dentro de la Tabla 1, sección 2). En este sentido, la caracterización del fraude fiscal como un acto de traición es sistemática. Por otro lado, Iglesias apela en ocasiones a referentes históricos cuando se dirige a su audiencia haciendo uso de expresiones metafóricas. En este sentido, el análisis previo muestra cómo el líder de Podemos establece una conexión contextual entre las personas que se rebelaron en Madrid contra la ocupación francesa de España a principios del siglo XIX con las que trabajan activamente por cambiar la situación económica y socio-política en España actualmente [i.e. (23)]. De manera adicional, Iglesias equipara la situación política actual en España con la del equipo de baloncesto 
masculino que compitió en la final olímpica contra el de Estados Unidos, queriendo así recalcar la oportunidad de vencer a un poderoso oponente. Por tanto, queda claro que el uso de eventos históricos nacionales constituye otro venero para la articulación de la idea del patriotismo constructivo a través del lenguaje metafórico por parte de Pablo Iglesias, algo que probablemente pretenda despertar el sentir patriótico de su audiencia. Aunque esté abierto a debate, se puede afirmar que esta evocación de acontecimientos históricos no es sino un ensalzamiento de elementos simbólicos nacionales. Si se da por buena esta interpretación, estaríamos ante otra característica compartida entre el patriotismo ciego y el patriotismo constructivo tal y como lo emplea Iglesias.

\section{Conclusión}

Este artículo ha analizado cómo Pablo Iglesias recurre a las metáforas para evocar y dar forma a su idea de patriotismo constructivo. Si bien es cierto que el presente análisis respalda en su mayoría los postulados teóricos y empíricos propuestos en la literatura, también cuestiona ciertos aspectos que habían sido descritos como características representativas de esta dimensión de patriotismo. En concreto, se pone en tela de juicio tres puntos que habían sido identificados como exclusivos del patriotismo ciego: la actitud negativa hacia miembros de otros grupos sociales, la identificación y confrontación de un enemigo común y el enaltecimiento de eventos históricos nacionales, que, por otra parte, puede analizarse como un ensalzamiento de elementos simbólicos. En el caso de Iglesias, estas tres estrategias discursivas son llevadas a cabo a través del "nosotros contra ellos”, una categorización sobre la que se basa la articulación de las distintas ideologías (Van Dijk 1998) y que, en teoría y tal y como se apunta en la sección 2, es más prominente en el patriotismo ciego. Esto sugiere que, en vez de una distinción clara, nos encontramos ante un fenómeno que puede ser ilustrado a través de un continuo en el que ambas dimensiones patrióticas se localizan polarizadas. Así, las características pormenorizadas anteriormente se localizarían a lo largo de dicho continuo, unas estando más próximas que otras a uno de los extremos, sin llegar a incurrir en exclusividad.

Para profundizar más en el asunto que nos concierne, sugerimos la implementación del mismo análisis examinando, esta vez, la dimensión ciega del patriotismo. Un análisis contrastivo extendería y complementaría la teoría existente que establece las diferencias y similitudes entre ambas variantes. Asimismo, consideramos que un enfoque intercultural podría arrojar interesantes 
resultados, ya que diferentes sistemas culturales establecen valores distintos en ciertas entidades y eventos (Gibbs y Cameron 2008), lo cual puede resultar en la aplicación de distintas estrategias discursivas para representar el patriotismo. Por último, tal y como apuntábamos anteriormente, el presente análisis puede verse mejorado por un análisis metafórico más detenido -seguramente centrado en un solo tipo de metáforas de los propuestos anteriormente- que busque proporcionar una explicación más exhaustiva de las características concretas del patriotismo constructivo.

\section{Bibliografía}

ADORNO, T. W. et al. (1950). The authoritarian personality. Nueva York: Harper. AYMES, J. R. (2004). "La literatura liberal en la Guerra de la Independencia: fluctuaciones y divergencias ideológico-semánticas en el empleo de los vocablos ‘pueblo', 'patria' y 'nación'” en La Ilusión Constitucional: Pueblo, Patria, Nación (Ed. Alberto Ramos Santana). Cádiz: Servicio de Publicaciones Universidad de Cádiz, 13-42.

BADER, M. J. (2006). “The Psychology of Patriotism”. The Phi Delta Kappan 87 (8): 582-584.

CHARTERIS-BLACK, J. (2004). Corpus Approaches to Critical Metaphor Analysis. Basingstoke, Nueva York: Palgrave-MacMillan.

CHARTERIS-BLACK, J. (2005). Politicians and Rhetoric: The persuasive power of metaphor. Basingstoke, Nueva York: Palgrave-MacMillan.

CHARTERIS-BLACK, J. (2008). Metaphors as Models of Political Leadership. <https://www.dur.ac.uk/resources/.../metaphors_as_models/:“Charteris2. pdf” $>$ (Consultado el 15 de abril de 2015).

CHARTERIS-BLACK, J. (2009). "Metaphor and Political Communication” en Metaphor and Discourse (eds. Andreas Musolff y Jörg Zinken). Basingstoke, Nueva York: Palgrave-MacMillan, 116-134.

CHILTON, P. (1996). Security metaphors: Cold war discourse from containment to common house. Nueva York: Peter Lang.

CHILTON, P. (2005). "Missing links in mainstream CDA: modules, blends and the critical instinct" en A New Agenda in (Critical) Discourse Analysis (eds. R. Wodak y P.Chilton). Ámsterdam: John Benjamins, 19-52.

DAVIDOV, E. (2011). "Nationalism and Constructive Patriotism: A Longitudinal Test of Comparability in 22 Countries with the ISSP”. International Journal of Public Opinion Research 23 (1): 88-103. 
EVANS, V. y GREEN, M. (2006). Cognitive Linguistics: An introduction. Edimburgo: Edinburgh University Press.

FAUCONNIER, G. (1994). Mental spaces: Aspects of meaning construction in natural language. Cambridge: Cambridge University Press.

FAUCONNIER, G. (1997). Mappings in Thought and Language. Cambridge: Cambridge University Press.

FAUCONNIER, G. y TURNER, M. (1998). “Conceptual integration networks”. Cognitive Science 22 (2): 133-187.

FAUCONNIER, G. y TURNER, M. (2002). The Way We Think: Conceptual blending and the mind's hidden complexities. Nueva York: Basic Books.

FINELLI, E. y ZOGMAISTER, C. (2015). "Blind and constructive patriotism, national symbols and outgroup attitudes”. Scandinavian Journal of Psychology 56 (2): 189-197.

GIBBS, R. W. y CAMERON, L. (2008). "The social-cognitive dynamics of metaphor performance”. Cognitive Systems Research 9: 64-75.

GLUCKSBERG, S. (1998). "Understanding Metaphors". Current Directions in Psychological Science 7 (2): 39-43.

HART, C. (2011). "Moving beyond metaphor in the Cognitive Linguistic Approach to CDA: Construal operations in immigration discourse" en Critical Discourse Studies in Context and Cognition (ed. Christopher Hart). Ámsterdam: John Benjamins, 171-192.

HART, C. (2008). "Critical Discourse Analysis and Metaphor: toward a theoretical framework”. Critical Discourse Studies 5 (2): 91-106.

HUDDY, L. y KHATIB, N. (2007). "American patriotism, national identity and political involvement”. American Journal of Political Science 51: 63-77.

LAKOFF, G. y JOHNSON, M. (1980). Metaphors We Live By. Chicago: University of Chicago Press.

LAKOFF, G. y JOHNSON, M. (1999). Philosophy in the flesh: The embodied mind and its challenge to Western thought. Nueva York: Basic Books.

LIVI, S. et al. (2014). "Values, ideological attitudes and patriotism”. Personality and Individual Differences 64: 141-146.

MIO, J. S. et al. (2005). "Presidential leadership and charisma: The effects of metaphor”. The Leadership Quarterly 16: 287-294.

MURO, D. y QUIROGA, A. (2005). "Spanish nationalism: Ethnic or civic?” Ethnicities 5 (1): 9-29.

MUSOLFF, A. (2012). "The study of metaphor as part of critical discourse analysis”. Critical Discourse Studies 9 (3): 301-310. 
NÚÑEZ-PERUCHA, B. (2011). “Critical Discourse Analysis and Cognitive Linguistics as tools for ideological research: A diachronic analysis of feminism” en Critical Discourse Studies in Context and Cognition (ed. Christopher Hart). Ámsterdam: John Benjamins, 97-118.

OED (2003). Shorter Oxford English dictionary. Oxford: Oxford University Press.

PARKER, C. S. (2010). "Symbolic versus Blind Patriotism: Distinction without Difference?” Political Research Quarterly 63 (1): 97-114.

PASCUAL, E. (2012). "Espacios mentales es integración conceptual” en Lingüística Cognitiva (eds. I. Ibarretxe y J. Valenzuela). Barcelona: Anthropos.

QARI, S. et al. (2012). "Patriotism, taxation and international mobility”. Public Choice 151: 695-717.

REAL ACADEMIA ESPAÑOLA. (2014). "Metáfora” en Diccionario de la lengua española (23a ed.). <http://dle.rae.es/?id=P4sce2c $>$.

REAL ACADEMIA ESPAÑOLA. (2014). "Patriotismo" en Diccionario de la lengua española (23a ed.). <http://dle.rae.es/?id=SBbAO70>.

SCHATZ, R. et al. (1999). "On the varieties of national attachment: Blind versus constructive patriotism”. Political Psychology 20: 151-174.

SPRY, C. y HORNSEY, M. (2007). "The influence of blind and constructive patriotism on attitudes toward multiculturalism and immigration”. Australian Journal of Psychology 59: 151-158.

STAUB, E. (1989). The roots of evil: The origins of genocide and other group violence. Nueva York: Cambridge University Press.

STAUB, E. (1991). "Blind versus constructive patriotism: Moving from embeddedness in the group to critical loyalty and action”. International Society for Political Psychology XIVth Annual Scientific Meeting (july 1-5, Helsinki).

STAUB, E. (1997). "Blind versus constructive patriotism: Moving from embeddedness in the group to critical loyalty and action" en Patriotism in the lives of individuals and nations (eds. D. Bar-Tal y E. Staub). Chicago: Nelson-Hall, 213-228.

SULLIVAN, J. L. et al. (1992). "Patriotism, politics, and the presidential election of 1988”. American Journal of Political Science 36: 200-234.

SOMMERVILLE, J. (1981). "Patriotism and war”. Ethics 91: 568-578.

VAN DIJK, T. A. (1998). "Opinions and Ideologies in the Press" en Approaches to Media Discourse (eds. Allan Bell y Peter Garrett). Oxford: Blackwell, 21-63. 
ApÉNDiCe 1: CONTEXTUALIZACiÓN DE LAS METÁFORAS INCLUIDAS EN EL TEXTO

\begin{tabular}{|c|c|c|c|}
\hline $\begin{array}{l}\text { Número } \\
\text { metáfora }\end{array}$ & Lugar & Fecha & Metáforas en su contexto \\
\hline 1 & Valencia & 25/01/15 & $\begin{array}{l}\text { La patria es tu gente. La patria es } \\
\text { poder llevar a tus hijos pequeños a una } \\
\text { escuela pública. La patria es que el } \\
\text { gobierno garantice que a los enfermos } \\
\text { de hepatitis les da la mejor medicación } \\
\text { (...). }\end{array}$ \\
\hline 2 & Madrid & $18 / 10 / 14$ & $\begin{array}{l}\text { Hablar de patria es hablar de otra cosa. } \\
\text { Es hablar de la dignidad de un pueblo } \\
\text { (...), es hablar de que tiene que haber } \\
\text { escuelas para que la gente pueda llevar } \\
\text { a los niños, es hablar de que tiene que } \\
\text { haber hospitales (...). Eso es sentirte } \\
\text { orgulloso de tu país. Sentirte orgulloso } \\
\text { de tener las mejores escuelas públicas, } \\
\text { sentirte orgulloso de tener los mejores } \\
\text { hospitales. (...) No es la casta la que } \\
\text { hace funcionar a un país. Es la gente, } \\
\text { esa es nuestra patria, la gente. }\end{array}$ \\
\hline 3 & Madrid & $24 / 02 / 15$ & $\begin{array}{l}\text { Pienso en los millones de ciudadanos } \\
\text { de este país. Ellos son los depositarios } \\
\text { últimos de la soberanía, ellos son el } \\
\text { país del que estoy orgulloso. Ellas y } \\
\text { ellos son mi patria. }\end{array}$ \\
\hline 4 & Madrid & $24 / 02 / 15$ & $\begin{array}{l}\text { Pienso en los millones de ciudadanos } \\
\text { de este país. Ellos son los depositarios } \\
\text { últimos de la soberanía, ellos son el } \\
\text { país del que estoy orgulloso. Ellas y } \\
\text { ellos son mi patria. }\end{array}$ \\
\hline 5 & Madrid & $24 / 02 / 15$ & $\begin{array}{l}\text { España es sus gentes, España es sus } \\
\text { ciudadanos. }\end{array}$ \\
\hline
\end{tabular}




\begin{tabular}{|c|c|c|c|}
\hline $\begin{array}{l}\text { Número } \\
\text { metáfora }\end{array}$ & Lugar & Fecha & Metáforas en su contexto \\
\hline 6 & Madrid & $15 / 11 / 14$ & $\begin{array}{l}\text { Pero frente al miedo está la sonrisa, } \\
\text { frente al miedo está la alegría. Hay } \\
\text { un país que defiende la alegría y la } \\
\text { dignidad. }\end{array}$ \\
\hline 7 & Madrid & $15 / 11 / 14$ & $\begin{array}{l}\text { Pero yo estoy harto de una concepción } \\
\text { de España agresiva (...) que diga a los } \\
\text { demás qué lengua tienen que hablar o } \\
\text { de qué nación se tienen que sentir. }\end{array}$ \\
\hline 8 & Madrid & $24 / 02 / 15$ & $\begin{array}{l}\text { A veces }[. . .] \text { hay que negociar }[. . .] \\
\text { poniendo mala cara porque estás } \\
\text { defendiendo a tu país, porque estás } \\
\text { defendiendo a tu gente. }\end{array}$ \\
\hline 9 & Almería & $17 / 05 / 15$ & $\begin{array}{l}\text { Todos esos solo tienen una patria, su } \\
\text { dinero. }\end{array}$ \\
\hline 10 & Madrid & $18 / 10 / 14$ & $\begin{array}{l}\text { No tienen más patria que sus cuentas } \\
\text { bancarias. }\end{array}$ \\
\hline 11 & Madrid & $31 / 01 / 15$ & $\begin{array}{l}\text { Nuestra patria no es una marca, nuestra } \\
\text { patria es la gente. Han querido humillar } \\
\text { a nuestro país con esa estafa que llaman } \\
\text { 'austeridad'. }\end{array}$ \\
\hline \multirow[t]{2}{*}{12} & Madrid & $31 / 01 / 15$ & $\begin{array}{l}\text { Nunca más España sin sus gentes, } \\
\text { nunca más España como marca para } \\
\text { que hagan negocios los ricos. }\end{array}$ \\
\hline & & & $\begin{array}{l}\text { La patria es tu gente. La patria es } \\
\text { poder llevar a tus hijos pequeños a } \\
\text { una escuela pública. La patria es } \\
\text { que el gobierno garantice que a los } \\
\text { enfermos de hepatitis les da la mejor } \\
\text { medicación. La patria es que si tu } \\
\text { abuelo está muy mayor, va a haber } \\
\text { alguien que le cuide. }\end{array}$ \\
\hline
\end{tabular}




\begin{tabular}{|c|c|c|c|}
\hline $\begin{array}{l}\text { Número } \\
\text { metáfora }\end{array}$ & Lugar & Fecha & Metáforas en su contexto \\
\hline 13 & Valencia & $25 / 01 / 15$ & $\begin{array}{l}\text { La patria es derecho a que te atiendan } \\
\text { en un hospital. [...] La patria es que } \\
\text { den la cara los responsable políticos } \\
\text { cuando hay un accidente. La patria es } \\
\text { poder sentirte orgulloso de los servicios } \\
\text { públicos y no de los mafiosos. }\end{array}$ \\
\hline 14 & Madrid & $24 / 05 / 15$ & $\begin{array}{l}\text { Pienso en los millones de ciudadanos } \\
\text { de este país. Ellos son los depositarios } \\
\text { últimos de la soberanía, ellos son el } \\
\text { país del que estoy orgulloso. Ellas y } \\
\text { ellos son mi patria. }\end{array}$ \\
\hline 15 & Almería & $17 / 05 / 14$ & $\begin{array}{l}\text { A los que entregan la soberanía de } \\
\text { nuestro país, a los que destruyen } \\
\text { el estado partiéndolo en pedacitos } \\
\text { entregándolo a sus amigos (...) a esos } \\
\text { hay que llamarles lo que son: traidores } \\
\text { a la patria, son traidores y deberían ser } \\
\text { juzgados como tales. }\end{array}$ \\
\hline 16 & Madrid & $31 / 01 / 15$ & $\begin{array}{l}\text { Nuestra patria no es una marca, nuestra } \\
\text { patria es la gente. Han querido humillar } \\
\text { a nuestro país con esa estafa que llaman } \\
\text { austeridad. Nunca más España sin sus } \\
\text { gentes, nunca más España como marca } \\
\text { para que hagan negocios los ricos. }\end{array}$ \\
\hline 17 & Valencia & 25/01/15 & $\begin{array}{l}\text { Yo digo que romper España es vender } \\
\text { España a la Troika. Yo digo que romper } \\
\text { España es cambiar el artículo } 135 \\
\text { de la Constitución con nocturnidad } \\
\text { y alevosía para entregar la soberanía } \\
\text { de nuestro país. Romper España es } \\
\text { privatizar la sanidad. Romper España } \\
\text { es privatizar la educación. }\end{array}$ \\
\hline
\end{tabular}




\begin{tabular}{|c|c|c|l|}
\hline $\begin{array}{c}\text { Número } \\
\text { metáfora }\end{array}$ & Lugar & Fecha & \multicolumn{1}{|c|}{ Metáforas en su contexto } \\
\hline 18 & Madrid & $24 / 02 / 15$ & $\begin{array}{l}\text { Pero necesitamos ricos responsables y } \\
\text { con un mínimo sentido del patriotismo. } \\
\text { No puede ser que solo se ajusten el } \\
\text { cinturón los de abajo mientras los de } \\
\text { arriba cada vez ganan más. }\end{array}$ \\
\hline 19 & Sevilla & $20 / 03 / 15$ & $\begin{array}{l}\text { Amar tu patria es indignarte cuando } \\
\text { hay gente que tiene que ir a comedores } \\
\text { sociales. Amar a tu patria no es llevar } \\
\text { pulseras de colores, es indignarte } \\
\text { cuando ves que gente que no tiene } \\
\text { trabajo no recibe ninguna prestación. }\end{array}$ \\
\hline 20 & Barcelona & $21 / 12 / 14$ & $\begin{array}{l}\text { Quien tiene las cuentas bancarias en } \\
\text { Suiza o en Andorra tiene un nombre: } \\
\text { traidor; traidores a su pueblo, no } \\
\text { tienen más patria que su dinero. }\end{array}$ \\
\hline 21 & Madrid & $18 / 10 / 14$ & $\begin{array}{l}\text { Y dijimos que los que rompen España } \\
\text { son los que tienen cuentas en Suiza o } \\
\text { en Andorra. }\end{array}$ \\
\hline Madrid & $31 / 01 / 15$ & $\begin{array}{l}\text { [después de hablar de la final olímpica } \\
\text { de baloncesto en Pekín 2008, donde } \\
\text { España quedó medalla de plata tras } \\
\text { enfrentarse a Estados Unidos y perder } \\
\text { por un estrecho margen] Yo creo que } \\
\text { estamos en una como esa. Podemos } \\
\text { ganarle el partido a los EEUU. }\end{array}$ \\
\hline $\begin{array}{l}\text { Luturo, de cambio, de dignidad y de valor. } \\
\text { 2 de mayo de 1808, no fueron los reyes ni } \\
\text { los generales ni los brillantes regimientos } \\
\text { del Palacio Real los que se opusieron a la } \\
\text { invasión. Fue el pueblo de Madrid, ese } \\
\text { que hoy está en la calle con nosotros, el } \\
\text { que compró con sacrificio la dignidad } \\
\text { frente a una invasión intolerable. }\end{array}$ \\
\hline $18 / 10 / 14$
\end{tabular}


ApÉNDICE 2: DiRECCIÓN URL DE LOS VIDEOS UTILIZADOS PARA EXTRAER LOS PASAJES QUE COMPONEN EL CORPUS

Almería 17/05/14: https://www.youtube.com/watch?v=Q1mf3UKGQWU Madrid 18/10/14: https://www.youtube.com/watch?v=FnpNArwJI6A Madrid 15/11/14: https:/www.youtube.com/watch?v=Rld9ePSO6ss Barcelona 21/12/14: https://www.youtube.com/watch?v=XBhS68S0xX0 Sevilla 18/01/15: https://www.youtube.com/watch?v=Kv3tS59GeG4 Valencia 25/01/15: https:/www.youtube.com/watch?v=eKe4q-KNoJ8 Madrid 31/01/15: https://www.youtube.com/watch?v=b4WoMdxJUwc Madrid 24/02/15: https://www.youtube.com/watch?v=gHyygNCXgBA Sevilla 20/03/15: https://www.youtube.com/watch?v=IRzC8p1YGGY 